\title{
Time to failure after definitive therapy for prostate cancer: implications for importance of aggressive local treatment
}

\author{
Al V. Taira, MD', Gregory S. Merrick, MD², Wayne M. Butler, PhD², Robert W. Galbreath, PhD², Ryan Fiano, BS, MPH², \\ Kent E. Wallner, MD³ , Edward Adamovich, MD4 \\ 'Dorothy Schneider Cancer Center, Mills-Peninsula Hospital, San Mateo, ${ }^{2}$ Schiffler Cancer Center \& Wheeling Jesuit University. Wheeling, \\ 3Puget Sound Healthcare Corporation, Group Health Cooperative, University of Washington, Seattle, ${ }^{4}$ Department of Pathology. \\ Wheeling Hospital, Wheeling, USA
}

\begin{abstract}
Purpose: To explore patterns of time to failure in men receiving high doses of permanent seed brachytherapy with or without external beam radiation therapy as a function of risk status.

Material and methods: Two thousand two hundred and thirty four patients were treated with prostate brachytherapy with median follow up of 8.0 years. The population was 35\% low risk, $49 \%$ intermediate risk, and $16 \%$ high risk (NCCN). Median day 0 implant $\mathrm{D}_{90}$ was $119 \%$ and $\mathrm{V}_{100}$ was $98 \%$. Treatment failure was defined as PSA $>0.40 \mathrm{ng} / \mathrm{mL}$ after nadir. Rates of biochemical failure, distant metastases, and prostate cancer death were determined with non-prostate death as a competing risk.

Results: For all patients, the 10-year biochemical failure, distant metastases, and cause-specific mortality were $4.4 \%$, $1.4 \%$, and $1.3 \%$, respectively. The biochemical failure rates were $1.3 \%, 4.8 \%$, and $10.0 \%$ for men with low, intermediate, and high risk disease, respectively. Median time to failure was 2.8 years. In men who died from prostate cancer, the median time from treatment failure to death was 4.2 years. Overall, $83 \%$ of biochemical failures and $97 \%$ of metastases occurred within the first 4 years after treatment.

Conclusions: With the dose escalation achieved by high quality brachytherapy dosimetry, even high-risk prostate cancer patients have excellent long term biochemical outcomes. Treatment failures occur early, and one third become metastatic and progress rapidly to prostate cancer death. The low frequency and pattern of failures suggest the presence of micrometastatic disease prior to treatment is rare, even in high risk patients.
\end{abstract}

J Contemp Brachytherapy 2013; 5, 4: 215-221 DOI: 10.5114/jcb.2013.39210

Key words: biochemical survival, brachytherapy dose escalation, cause specific survival, metastases free survival, prostate cancer.

\section{Purpose}

There is emerging evidence that time to biochemical failure is a robust prognostic factor for prostate cancer mortality and overall mortality in men receiving definitive radiotherapy [1-3]. Interval to biochemical failure is also highly prognostic for prostate cancer mortality in men undergoing prostatectomy [4]. One cause of early biochemical failure is occult micrometastatic disease present at time of treatment. Regardless of efficacy of local treatment, individuals with occult metastases often have early recurrence with relatively poor prognosis, due to unappreciated stage IV disease at presentation. Early biochemical failure can also occur in men with strictly localized disease, if local therapy is inadequate to provide even short term local control. This can be due to radioresistant local disease, inade- quate radiation dose delivered, inadequate surgical margin or deficient radiation targeting.

As with early failures, late failures can be caused either by more gradual progression of slow growing occult metastatic disease or gradual recurrence of partially treated local disease. In modern radiation therapy literature, there continues to be a relatively large number of late failures ( $>4$ years), even with dose escalation to 78 Gy or over 80 Gy $[5,6]$. The purpose of this paper is to explore whether further dose escalation would lead to a decrease in late failures. If so, particularly for high risk patients, this might suggest that the preponderance of late failures in recent studies may represent incomplete ability to eradicate local disease rather than high incidence of slow growing occult metastases at presentation.

In this paper, we examine a cohort of men who received high local radiation doses for clinically localized prostate 
cancer. Consistently, high implant $\mathrm{D}_{90} \mathrm{~s}$ with sizeable margins were utilized for all patients, and the majority of intermediate risk and almost all high risk patients received supplemental external beam radiation. Our goal was to explore patterns in time to failure in men receiving high local radiation doses to better understand the role of improved local control and the implications for long term prostate cancer outcomes. We also hope to provide some insight into the question of what portion of patients (particularly high risk patients) are potentially curable, in effect, without viable metastatic disease at presentation.

\section{Material and methods}

From March 1995 till July 2010, 2234 consecutive patients underwent definitive permanent interstitial brachytherapy by a single brachytherapist (GSM). All patients were treated more than three years prior to analysis. All biopsy samples were reviewed by a single pathologist (EA) to minimize inconsistencies in pathologic grading. Preplanning technique, intraoperative approach and dosimetric evaluation have been described in detail [7,8]. Categorized by National Comprehensive Cancer Network (NCCN) risk group, the cohort consisted of 785 men with low risk, 1098 with intermediate risk, and 351 men with high risk disease.

Of the 2234 patients, 1111 (50.3\%) received supplemental external beam radiotherapy and 748 (33.5\%) received androgen deprivation therapy. Supplemental external beam and androgen deprivation was utilized primarily for intermediate and high risk patients. Supplemental external beam was delivered to $69.6 \%$ and $96.3 \%$ of intermediate and high risk patients, respectively. Androgen deprivation therapy (ADT) was used in $27.4 \%$ and $71.8 \%$ of intermediate and high risk patients. When employed, supplemental external beam radiotherapy was generally used in a dose of 45-50.4 Gy covering prostate, seminal vesicles, and at-risk pelvic nodes. ADT, when utilized, was initiated 3 months prior to implantation, and consisted of a luteinizing hormone-releasing hormone (LHRH) agonist and an anti-androgen. The range of ADT duration was 3-36 months. Indications for ADT were prostate cytoreduction prior to implant and for men with higher risk disease.

For prostate implants, the target volume (PTV) was the prostate plus a periprostatic margin of 4-5 mm, except posteriorly to limit rectal dose. Median prostate volume was $32.0 \mathrm{~cm}^{3}$, while the median planning volume was $60.6 \mathrm{~cm}^{3}$. Also included in the brachytherapy PTV was the proximal $1.0 \mathrm{~cm}$ of seminal vesicles.

The primary radionuclide utilized was ${ }^{103} \mathrm{Pd}$ (Theragenics model 200), while the other radionuclide ${ }^{125} \mathrm{I}$ (Amersham model 6711 and its stranded form) was not implanted after 2003. Dosimetry was based on day zero computerized tomography (CT) studies. The overall population mean $\mathrm{D}_{90}$ (minimum dose received by $90 \%$ of the PTV) was $119.1 \%$ of prescription dose. The mean $V_{100}$ for the study population was $96.6 \%$ of the PTV. These relatively large $D_{90}$ and $V_{100}$ values have been associated with improved treatment outcomes $[9,10]$.

Biologically effective dose (BED) was calculated using the algorithm recommended by American Association of
Physicist in Medicine (AAPM) Task Group 137 to provide consistency in radiobiological comparisons between institutions [11]. This consensus group recommends a uniform set of algorithms and radiobiological indices to facilitate consistency in routine outcome reporting. The Task Group values used in this work were: $\alpha=0.15 \mathrm{~Gy}^{-1}$, $\beta=0.05 \mathrm{~Gy}^{-2}, \alpha / \beta=3.0 \mathrm{~Gy}, \mathrm{~T}_{\text {pot }}=42$ days, and repair half-life $=16 \mathrm{~min}$.

The brachytherapy BED was based on the day $0 D_{90}$, and the total BED added any contribution from external beam radiation.

Patient demographics and treatment details are provided in Table 1, which is stratified by National Comprehensive Cancer Network (NCCN) risk groups. Patients were monitored by physical examination including digital rectal examination, and serum PSA determination at 3 and 6 months intervals. Patient survival was confirmed for all patients not only by PSA reports, but also by frequent quality of life surveys (QoL) (by telephone or occasionally mail) at least 25 times during the first five years following brachytherapy, and never less than twice per year thereafter. The primary outcome measures were time to biochemical failure, time to distant metastases, and time to prostate cancer death. We also assessed percent of men with biochemical failure who ultimately progressed to metastases or prostate cancer death, and the time from biochemical failure to those outcomes. Biochemical failure was defined as PSA $>0.40 \mathrm{ng} / \mathrm{mL}$ after nadir [12]. This definition has been shown to be particularly sensitive in detecting treatment failure [12]. Cause of death was determined for each deceased patient. Patients with metastatic prostate cancer or castrate resistant disease without obvious metastases who died of any cause were classified as dead of prostate cancer. All other deaths were attributed to the immediate cause of death. In our population, $40 \%$ of deaths were attributable to cardiovascular disease, 33\% to non-prostate cancer deaths, $8 \%$ to respiratory disease, $4 \%$ to prostate cancer, and $15 \%$ to other causes.

Continuous clinical and treatment variables were compared across groups, using one-way analysis of variance (ANOVA). Categorical variables were compared using a chi-square analysis. Biochemical survival, metastases free survival, cause specific mortality, and all cause mortality were determined using cumulative incidence and cumulative survival curves. With the population stratified by low, intermediate, and high risk disease, biochemical failure rates were determined by competing risk analysis where non-prostate cancer death was the competitor. Significant predictors for prostate specific, biochemical progression free, and overall survival were first determined by univariate regression analysis, and those variables with $p<0.010$ were included in multivariate analysis. Competing risk regression was employed for prostate specific and progression free survival analyses. All statistical analyses used Stata version 13.0 software (StataCorp, College Station, TX, USA), and statistical significance was defined a $p<0.05$.

\section{Results}

For the population, 10 year overall mortality and competing risk adjusted biochemical failure, and cause-spe- 
Table 1. Clinical parameters of the study population, stratified by NCCN risk classification

\begin{tabular}{|c|c|c|c|c|c|c|c|c|c|c|}
\hline \multirow{2}{*}{\multicolumn{2}{|c|}{ Continuous variables }} & \multicolumn{2}{|c|}{$\begin{array}{l}\text { Low risk } \\
(n=785)\end{array}$} & \multicolumn{2}{|c|}{$\begin{array}{c}\text { Intermediate risk } \\
\quad(n=1098)\end{array}$} & \multicolumn{2}{|c|}{$\begin{array}{l}\text { High risk } \\
(n=351)\end{array}$} & \multirow[t]{2}{*}{$p^{1}$} & \multicolumn{2}{|c|}{$\begin{array}{c}\text { Total } \\
(n=2234)\end{array}$} \\
\hline & & Med. (IQR) & Mean & Med. (IQR) & Mean & Med. (IQR) & Mean & & Med. (IQR) & Mean \\
\hline \multicolumn{2}{|l|}{ Age at implant } & $64(11)$ & 63.2 & $66(10)$ & 65.6 & $67(11)$ & 66.4 & $<0.001$ & 66 (11) & 64.9 \\
\hline \multicolumn{2}{|c|}{ Follow-up (years) } & $8.0(5.7)$ & 8.4 & $8.2(5.7)$ & 8.5 & $7.6(6.0)$ & 8.1 & 0.280 & $8.0(5.8)$ & 8.4 \\
\hline \multicolumn{2}{|l|}{ PSA (ng/mL) } & $5.5(2.2)$ & 5.6 & $6.6(4.5)$ & 7.6 & $9.6(14.4)$ & 14.0 & $<0.001$ & $6.2(3.9)$ & 7.9 \\
\hline \multicolumn{2}{|l|}{ Gleason score } & $6.0(0)$ & 5.9 & $7.0(0)$ & 6.9 & $8.0(1)$ & 8.1 & $<0.001$ & $7.0(1)$ & 6.7 \\
\hline \multicolumn{2}{|l|}{$\begin{array}{l}\text { Percent positive } \\
\text { biopsies }\end{array}$} & $16.7(20.8)$ & 23.6 & $34.6(27.8)$ & 41.2 & $50.0(38.1)$ & 53.2 & $<0.001$ & $33.3(33.3)$ & 36.9 \\
\hline \multicolumn{2}{|l|}{$\mathrm{BMI}\left(\mathrm{kg} / \mathrm{m}^{2}\right)$} & $27.7(5.2)$ & 28.2 & $27.7(5.5)$ & 28.5 & $28.0(5.4)$ & 28.9 & 0.064 & $27.8(5.4)$ & 28.4 \\
\hline \multicolumn{2}{|c|}{ Prostate volume $\left(\mathrm{cm}^{3}\right)$} & $34.0(10.1)$ & 34.5 & 31.9 (11.8) & 32.4 & $26.4(14.8)$ & 28.2 & $<0.001$ & $32.0(11.8)$ & 32.5 \\
\hline \multicolumn{2}{|c|}{ Planning volume $\left(\mathrm{cm}^{3}\right)$} & $63.4(15.2)$ & 63.7 & $60.4(17.5)$ & 60.2 & $52.0(20.0)$ & 53.8 & $<0.001$ & $60.6(17.5)$ & 60.4 \\
\hline \multicolumn{2}{|c|}{$\mathrm{V}_{100}(\%$ volume $)$} & $97.8(3.3)$ & 96.4 & $98.0(3.1)$ & 96.6 & $98.2(3.1)$ & 96.9 & 0.165 & $97.9(3.2)$ & 96.6 \\
\hline \multicolumn{2}{|l|}{$V_{150}(\%$ volume $)$} & $69.3(13.1)$ & 66.6 & $71.4(12.9)$ & 68.7 & $73.2(13.4)$ & 70.4 & $<0.001$ & $71.0(13.5)$ & 68.2 \\
\hline \multicolumn{2}{|l|}{$V_{200}(\%$ volume $)$} & $38.6(13.6)$ & 36.8 & $41.3(12.8)$ & 39.7 & $43.6(12.7)$ & 41.8 & $<0.001$ & $40.8(13.3)$ & 39.0 \\
\hline \multicolumn{2}{|c|}{$\mathrm{D}_{90}(\%$ prescribed dose $)$} & $118.0(14.3)$ & 117.6 & $119.5(15.8)$ & 119.5 & $121.2(18.0)$ & 121.1 & $<0.001$ & $119.2(15.6)$ & 119.1 \\
\hline \multicolumn{2}{|c|}{ Brachytherapy BED (Gy) } & $132.4(20.1)$ & 132.1 & $118.6(36.5)$ & 115.8 & $94.3(20.6)$ & 97.0 & $<0.001$ & $122.6(36.6)$ & 118.6 \\
\hline \multicolumn{2}{|l|}{ Total BED (Gy) } & $133.1(20.3)$ & 133.7 & $156.9(27.0)$ & 154.1 & $163.5(17.6)$ & 162.5 & $<0.001$ & $149.2(31.5)$ & 148.2 \\
\hline \multicolumn{2}{|c|}{ Most Recent PSA } & $<0.02(0.02)$ & 0.03 & $<0.02(0.02)$ & 0.03 & $<0.02(0.01)$ & 0.02 & 0.059 & $<0.02(0.01)$ & 0.03 \\
\hline \multicolumn{2}{|c|}{ Categorical variables } & Count & (\%) & Count & $(\%)$ & Count & $(\%)$ & $p^{*}$ & Count & $(\%)$ \\
\hline \multirow[t]{2}{*}{ Clinical stage: } & $\mathrm{T} 1 \mathrm{~b}-\mathrm{T} 2 \mathrm{a}$ & 785 & $(100)$ & 942 & $(85.8)$ & 235 & $(67.0)$ & \multirow[t]{2}{*}{$<0.001$} & 1961 & $(87.8)$ \\
\hline & $\mathrm{T} 2 \mathrm{~b}-\mathrm{T} 3 \mathrm{c}$ & 0 & $(0.0)$ & 156 & $(14.2)$ & 116 & $(33.0)$ & & 273 & $(12.2)$ \\
\hline \multirow[t]{2}{*}{ Isotope: } & ${ }^{103} \mathrm{Pd}$ & 604 & $(76.9)$ & 1016 & $(92.5)$ & 339 & $(96.6)$ & $<0.001$ & 1959 & $(87.7)$ \\
\hline & 125 & 181 & $(23.1)$ & 82 & $(7.5)$ & 12 & (3.4) & & 275 & $(12.3)$ \\
\hline ADT: & None & 590 & $(75.2)$ & 797 & $(72.6)$ & 99 & $(28.2)$ & $<0.001$ & 1486 & $(66.5)$ \\
\hline & $\leq 6$ months & 187 & $(23.8)$ & 207 & $(18.8)$ & 49 & $(14.0)$ & & 443 & (19.8) \\
\hline & $>6$ months & 8 & $(1.0)$ & 94 & (8.6) & 203 & $(57.8)$ & & 305 & $(13.7)$ \\
\hline XRT: & No & 764 & $(97.3)$ & 334 & (30.4) & 13 & (3.7) & $<0.001$ & 1111 & $(49.7)$ \\
\hline & Yes & 21 & $(2.7)$ & 764 & $(69.6)$ & 338 & $(96.3)$ & & 1123 & $(50.3)$ \\
\hline Hypertension: & No & 410 & $(52.2)$ & 543 & $(49.5)$ & 156 & $(44.4)$ & 0.052 & 1109 & $(49.6)$ \\
\hline & Yes & 375 & $(47.8)$ & 555 & $(50.5)$ & 195 & (55.6) & & 1125 & $(50.4)$ \\
\hline Diabetes: & No & 711 & $(90.6)$ & 958 & $(87.2)$ & 305 & $(86.9)$ & 0.055 & 1974 & $(88.4)$ \\
\hline & Yes & 74 & $(9.4)$ & 140 & $(12.8)$ & 46 & (13.1) & & 260 & $(111.6)$ \\
\hline Cardiovascu- & No & 675 & $(86.0)$ & 906 & $(82.5)$ & 283 & $(80.6)$ & 0.041 & 1864 & $(83.4)$ \\
\hline & Yes & 110 & (14.0) & 192 & $(17.5)$ & 68 & (19.4) & & 370 & (16.6) \\
\hline Testosterone ${ }^{\dagger}$ : & Lower tertile & 352 & $(68.4)$ & 473 & $(68.0)$ & 144 & $(65.4)$ & 0.425 & 969 & $(67.7)$ \\
\hline & Middle tertile & 130 & $(25.2)$ & 160 & $(23.0)$ & 56 & $(25.5)$ & & 346 & $(24.2)$ \\
\hline & Upper tertile & 33 & $(6.4)$ & 63 & (9.0) & 20 & (9.1) & & 116 & $(8.1)$ \\
\hline Perineural & No & 720 & $(91.7)$ & 654 & $(59.6)$ & 172 & $(49.0)$ & $<0.001$ & 1546 & $(69.2)$ \\
\hline & Yes & 65 & (8.3) & 444 & $(40.4)$ & 179 & (51.0) & & 688 & $(30.8)$ \\
\hline
\end{tabular}

${ }^{1}$ One-Way ANOVA

§SA values only for non-biochemical failures, $n=2131$ ${ }^{*} \chi^{2}$

${ }^{\dagger}$ Based on 1431 with testosterone values

NCCN - National Comprehensive Cancer Network, IQR - inter quartile range, PSA - prostate specific antigen, BMI-body mass index, BED - biologically effective dose based on brachytherapy day zero $D_{90} \pm$ any external beam, $A D T$-androgen deprivation therapy, XRT-external beam radiation therapy

cific mortality were $22.5 \%, 4.4 \%$, and $1.3 \%$, respectively (Fig. 1). No metastases developed after 5 years, and the cumulative incidence of distant metastases at 5 years and beyond was $1.4 \%$. The cumulative ten year competing risk adjusted biochemical failure rate for men with low, intermediate, and high risk disease was $1.3 \%, 4.8 \%$, and $10.0 \%$, respectively (Fig. 2). The median time to failure (TTF) was 2.8 years. 


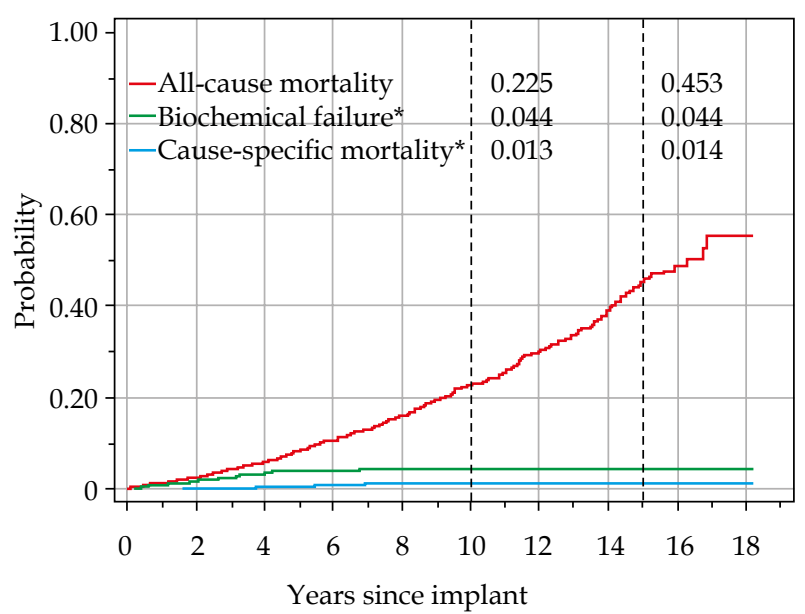

${ }^{*}$ Cumulative incidence with non-prostate specific death as a competing risk

Fig. 1. Probabilities for all-cause mortality, biochemical failure, and cause-specific mortality are summarized at 10 years and 15 years post implant for the 2,234 patients in the population

Because completeness of follow up influences the validity of survival curves, Table 2 lists mean days since last contact of living patients for mortality and days since last PSA for biochemical failure. The mean elapsed days since last patient contact (64 \pm 117 days), and last PSA (123 \pm 164 days) were considerably greater than the medians (50 days and 99 days, respectively) because of a few outliers. For survival status, only 11 of 1713 living patients had not been contacted in the year preceding database closure. Nine of the eleven had either advanced dementia or were dying from a disease other than prostate cancer, and the patient or caregiver felt that further follow up and

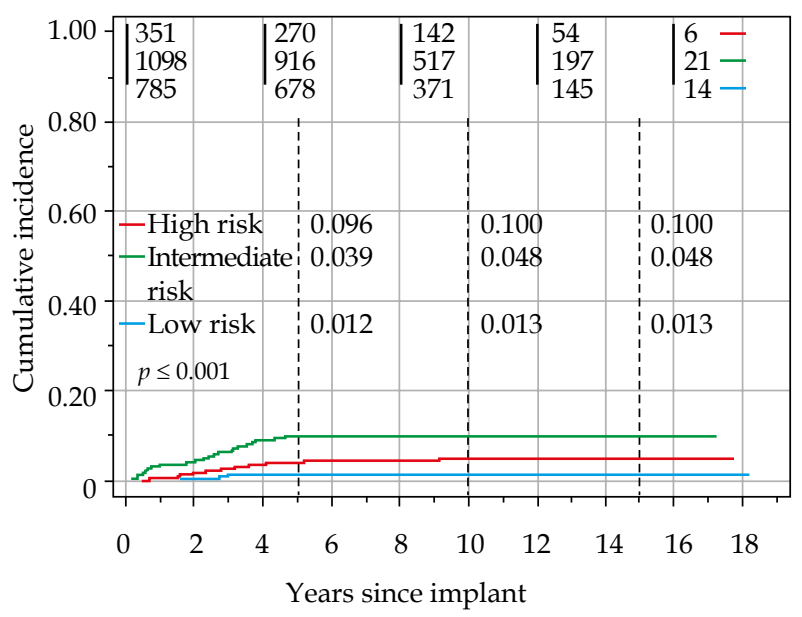

Fig. 2. Cumulative incidence of biochemical failure with non-prostate death as a competing risk, stratified by NCCN risk group, is summarized at 5,10 , and 15 years post implant. The number of patients remaining at risk in four year increments is listed at the top, stratified by risk group

PSA testing were pointless. For biochemical survival follow up, PSA testing was more than one year delinquent in 57 of 1664 living, non-failed men. The most common reason for non-compliance was the inconvenience and expense of testing, followed by perceived futility among those dying from non-prostate causes.

There was no biochemical failure in any of the 745 patients followed for more than 9.2 years, out to the maximum PSA follow up of 18.2 years. The median TTF among the biochemical failures was 2.6 years, and there was no significant difference between risk groups $(p=0.077)$ where the mean TTF for low, intermediate, and high risk

Table 2. Time dependent outcomes stratified by NCCN risk group

\begin{tabular}{|c|c|c|c|c|c|c|c|c|c|}
\hline \multirow[t]{2}{*}{ Continuous variables } & \multicolumn{2}{|c|}{ Low risk } & \multicolumn{2}{|c|}{ Intermediate risk } & \multicolumn{2}{|c|}{ High risk } & \multirow[t]{2}{*}{$p^{1}$} & \multicolumn{2}{|c|}{ Total } \\
\hline & Med. (IQR) & $n$ & Med. (IQR) & $n$ & Med. (IQR) & $n$ & & Med. (IQR) & $n$ \\
\hline Age at death (years) & $76.6(10.7)$ & 142 & $77.2(8.4)$ & 270 & $77.4(7.3)$ & 109 & 0.044 & $77.1(8.7)$ & 521 \\
\hline $\begin{array}{l}\text { Years: implant to } \\
\text { all-cause death }\end{array}$ & $6.0(6.3)$ & 142 & $7.0(4.3)$ & 270 & $6.9(6.5)$ & 109 & 0.271 & $6.7(5.7)$ & 521 \\
\hline $\begin{array}{l}\text { Years: implant to } \\
\text { prostate death }\end{array}$ & $4.3(0)$ & 1 & $7.3(2.6)$ & 9 & $5.7(3.5)$ & 12 & 0.141 & $6.5(3.0)$ & 22 \\
\hline $\begin{array}{l}\text { Years: implant to } \\
\text { metastases }\end{array}$ & $3.3(1.1)$ & 2 & $2.3(1.6)$ & 11 & $1.9(1.9)$ & 17 & 0.278 & $2.3(2.0)$ & 30 \\
\hline $\begin{array}{l}\text { Years: failure to } \\
\text { prostate death }\end{array}$ & $1.6(0)$ & 1 & $5.0(3.3)$ & 9 & $3.1(3.0)$ & 12 & 0.076 & $4.2(3.8)$ & 22 \\
\hline $\begin{array}{l}\text { Years to biochemical } \\
\text { failure }\end{array}$ & $2.2(1.9)$ & 10 & $2.7(2.1)$ & 48 & $2.4(2.5)$ & 34 & 0.077 & $2.6(2.0)$ & 92 \\
\hline $\begin{array}{l}\text { Days since last } \\
\text { contact* }^{*}\end{array}$ & $50(62)$ & 643 & $50(62)$ & 828 & $50(63)$ & 242 & 0.833 & $50(62)$ & 1713 \\
\hline Days since last PSA $\S$ & $99(95)$ & 636 & $98.5(96)$ & 800 & 106 (109) & 228 & 0.547 & 99 (99) & 1664 \\
\hline
\end{tabular}

\section{${ }^{1}$ One-Way ANOVA}

*Elapsed days from last patient contact to database closure on $25 \mathrm{Jul} 2013$ for all living patients (11 of 1713 living patients had not been contacted in the year prior to database closure)

§Elapsed days from last PSA to database closure on $25 \mathrm{Jul} 2013$ for all living, non-biochemical failures (57 of 1664 patients had not had a PSA determination in the year prior to database closure)

NCCN - National Comprehensive Cancer Network, SD - standard deviation, PSA - prostate specific antigen 


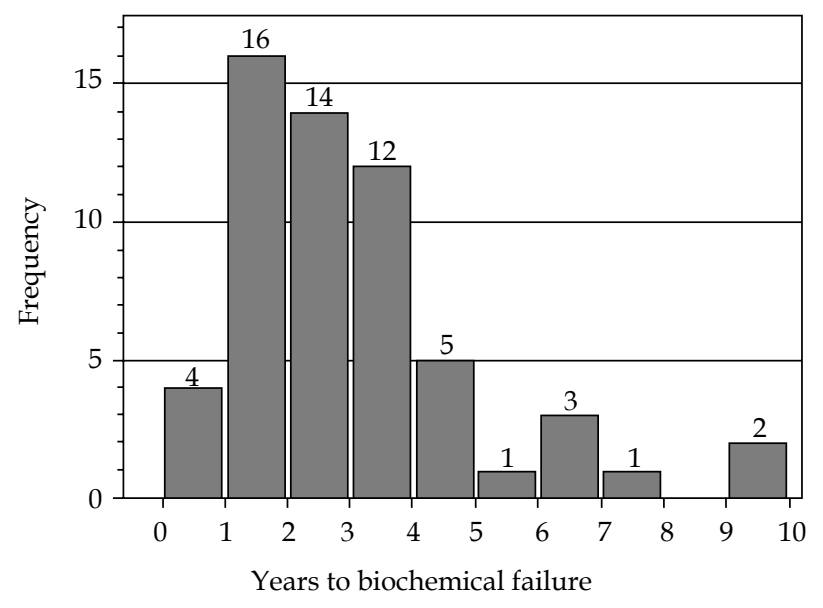

Fig. 3. Time to failure histogram for the 58 biochemical failures in low and intermediate risk patients

men was $2.5 \pm 1.8,3.2 \pm 2.0$, and $2.3 \pm 1.5$ years, respectively. Overall, $82.6 \%$ of biochemical failures occurred within the first four years after treatment. In men with low and intermediate risk disease (Fig. 3), 79.3\% of biochemical failures occurred within the first four years, compared to $88.2 \%$ of failures in men with high risk disease (Fig. 4).

In men who died from prostate cancer, the median time from treatment failure to death was 4.2 years. Median time from treatment to development of metastases was 2.3 years. Overall, $96.7 \%$ of metastases occurred within the first 4 years.

Table 3 consists of univariate and multivariate analyses of cause-specific, biochemical progression free, and overall survival. Of the eight variables identified as significant predictors of biochemical progression free survival, six of them - PSA, Gleason score, clinical stage, percent positive biopsies, and ADT duration are strongly correlated with NCCN risk grouping. For overall survival, only two of the 15 variables included in the multivariate analysis were significant predictors: age at implant and tobacco use.

\section{Discussion}

Early failure after definitive prostate cancer treatment was significantly more common in the 1990s when lower radiation doses were employed. As an example, in the D'Amico et al. landmark 1998 paper comparing biochemical outcomes between prostatectomy, surgery and brachytherapy [13], the authors report on high risk men treated with $66 \mathrm{~Gy}$ of radiotherapy without ADT. Over $50 \%$ of men had failed therapy before 3 years. Likewise, Kestin et al. [14] reported in 1999 on William Beaumont patients, primarily Gleason $\leq 7$, treated to a median dose of 66.6 Gy. They found a median time to failure of less than two years, with a failure rate approximating $50 \%$ at three years and relatively few failures after that time. These high rates of early local failure were likely due to both the more advanced disease common during that era, and to the inadequacy of $66 \mathrm{~Gy}$ to reliably eradicate local disease.

The increase in radiotherapy dose to 70 Gy with and without the addition of androgen deprivation, led to a de-

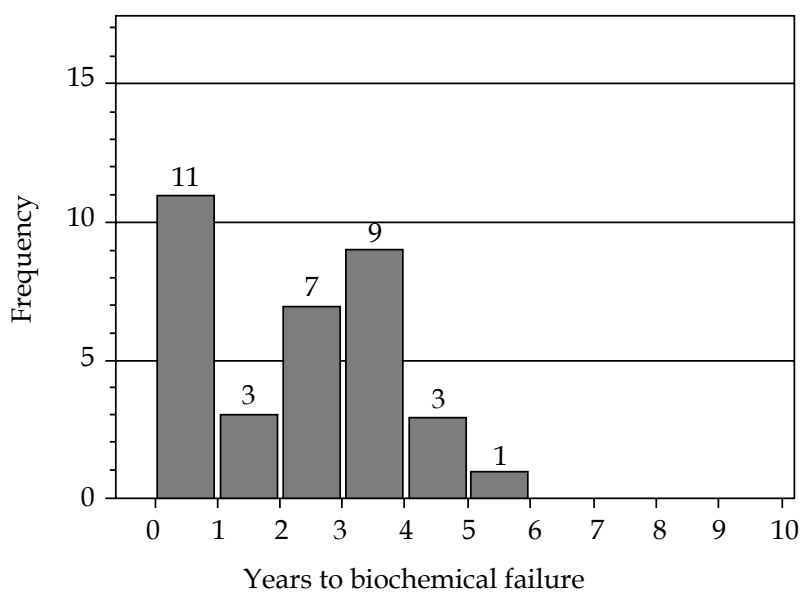

Fig. 4. Time to failure histogram for the 34 biochemical failures in high-risk patients

crease in early failures. In the milestone EORTC trial published by Bolla et al. [15], which demonstrated the survival advantage of androgen deprivation combined with 70 Gy radiotherapy, biochemical failures were relatively uncommon in either arm in the first three years. However, ultimate biochemical failure rates were high, with the significant majority of treatment failures occurring in the fourth year and later. At 3 years, biochemical failure was approximately $15-20 \%$ in both arms. However, by year 8 , failure rates were approximately $50 \%$ in the ADT arm and $80 \%$ in the radiotherapy only arm.

As radiation doses have been increased, the overall rate of treatment failure has decreased, though the proportion of late treatment failures remains high. The M.D. Anderson dose escalation trial reported by Kuban et al. [5], compared men receiving $70 \mathrm{~Gy}$ to those receiving $78 \mathrm{~Gy}$. With dose escalation, early treatment failures were uncommon; the overall number of treatment failures decreased; and the number of late failures decreased. However, the significant majority of treatment failures continued to occur after four years. The PROG dose escalation study [16] has shown similar results, with the significant majority of low and intermediate risk failures occurring in the fourth year or later in the high dose arm. Recently, Zelefsky et al. [6] reported on their prospective dose escalation, comparing men treated to < $81 \mathrm{~Gy}$, with those treated up to $86.4 \mathrm{~Gy}$. They found a modest decrease in treatment failures within the first four years, with a more prominent decrease in later failures. Nonetheless, even at doses $>81 \mathrm{~Gy}$, the vast majority of failures occurred after four years, whether or not androgen deprivation was used. And overall treatment failure at ten years remained high at approximately $25 \%$ for intermediate risk patients and $45 \%$ for high risk patients. In high risk patients, the combination of moderate dose external beam radiation therapy, a brachytherapy boost and ADT decreases biochemical failure and prostate cancer deaths, when compared to patients treated with external beam and ADT [17].

These findings demonstrate that some early failures and many late failures can be eliminated with dose escalation to approximately $80 \mathrm{~Gy}$, presumably because many of the failures at lower doses were related to inadequate 
Table 3. Univariate and multivariate analysis of cause-specific, biochemical progression free, and overall survival in the study population of 2234 patients

\begin{tabular}{|c|c|c|c|c|c|c|c|c|c|c|c|c|}
\hline \multirow[t]{4}{*}{ Variable } & \multicolumn{12}{|c|}{ Survival } \\
\hline & \multicolumn{4}{|c|}{$\begin{array}{l}\text { Prostate-specific }{ }^{\mathrm{CR}} \\
(n=22 \text { PS deaths) }\end{array}$} & \multicolumn{4}{|c|}{$\begin{array}{l}\text { Biochemical progression free }{ }^{\mathrm{CR}} \\
\quad(n=92 \text { failures })\end{array}$} & \multicolumn{4}{|c|}{$\begin{array}{c}\text { Overall }^{*} \\
(n=521 \text { deaths })\end{array}$} \\
\hline & \multicolumn{2}{|c|}{ Univariate } & \multicolumn{2}{|c|}{ Multivariate } & \multicolumn{2}{|c|}{ Univariate } & \multicolumn{2}{|c|}{ Multivariate } & \multicolumn{2}{|c|}{ Univariate } & \multicolumn{2}{|c|}{ Multivariate } \\
\hline & $p$ & $\mathrm{HR}$ & $p$ & $\mathrm{HR}$ & $p$ & HR & $p$ & $\mathrm{HR}$ & $p$ & $H R$ & $p$ & $\mathrm{HR}$ \\
\hline Age at implant & 0.721 & & & & 0.795 & & & & $<0.001$ & 1.096 & $<0.001$ & 1.121 \\
\hline PSA & $<0.001$ & 1.044 & 0.072 & & $<0.001$ & 1.053 & $<0.001$ & 1.063 & 0.081 & 1.011 & 0.307 & \\
\hline Gleason score & $<0.001$ & 3.015 & $<0.001$ & 3.405 & $<0.001$ & 1.863 & $<0.001$ & 2.016 & $<0.001$ & 1.229 & 0.355 & \\
\hline Clinical stage & $<0.001$ & 1.981 & 0.215 & & $<0.001$ & 1.792 & 0.003 & 1.370 & $<0.001$ & 1.167 & 0.092 & \\
\hline $\begin{array}{l}\text { Percent positive } \\
\text { biopsy }\end{array}$ & $<0.001$ & 1.031 & 0.281 & & $<0.001$ & 1.027 & $<0.001$ & 1.017 & $<0.001$ & 1.006 & 0.278 & \\
\hline Perineural invasion & 0.050 & 2.309 & 0.985 & & $<0.001$ & 2.180 & 0.453 & & 0.085 & 1.176 & 0.307 & \\
\hline $\mathrm{BMI}$ & 0.960 & & & & 0.631 & & & & 0.031 & 0.977 & 0.545 & \\
\hline Prostate volume & 0.271 & & & & 0.099 & 1.018 & 0.002 & 1.035 & 0.974 & & & \\
\hline$V_{100}$ & 0.697 & & & & 0.076 & 0.975 & 0.882 & & 0.640 & & & \\
\hline Brachytherapy BED & $<0.001$ & 0.971 & 0.550 & & $<0.001$ & 0.983 & 0.611 & & 0.094 & 0.997 & 0.082 & \\
\hline Total BED & 0.072 & 1.022 & 0.822 & & 0.025 & 1.013 & 0.911 & & 0.282 & & & \\
\hline ADT duration & 0.002 & 1.055 & 0.056 & & 0.016 & 1.030 & $<0.001$ & 0.926 & 0.050 & 1.012 & 0.534 & \\
\hline XRT (yes vs. no) & 0.004 & 5.938 & 0.737 & & $<0.001$ & 2.539 & 0.753 & & 0.037 & 1.198 & 0.730 & \\
\hline Hypertension & 0.003 & 0.163 & 0.010 & 0.181 & 0.388 & & & & 0.034 & 1.205 & 0.860 & \\
\hline Hypercholesterolemia & 0.045 & 0.224 & 0.353 & & $<0.001$ & 0.355 & 0.043 & 0.544 & 0.655 & & & \\
\hline Diabetes & 0.325 & & & & 0.816 & & & & $<0.001$ & 1.577 & 0.370 & \\
\hline $\begin{array}{l}\text { Coronary artery } \\
\text { disease }\end{array}$ & $<0.001$ & $7^{\star} 10^{-20}$ & $<0.001$ & $2^{*} 10^{-7}$ & 0.006 & 0.284 & 0.009 & 0.292 & $<0.001$ & 1.797 & 0.111 & \\
\hline Testosterone & 0.158 & & & & 0.808 & & & & 0.059 & 1.115 & 0.347 & \\
\hline $\begin{array}{l}\text { Tobacco (never vs. } \\
\text { former vs. current) }\end{array}$ & 0.796 & & & & 0.501 & & & & $<0.001$ & 1.497 & $<0.001$ & 1.952 \\
\hline
\end{tabular}

local disease control. However, the preponderance of late failures even at dose levels of 78-86 Gy, leaves open the question as to whether men in those studies had occult metastases at presentation or were potentially curable with even further dose escalation.

With mean and median brachytherapy day 0 implant $D_{90}$ s of $119 \%$, generous margins with the prostate volume expanded by a factor of 1.9 to the planning volume, and extensive use of supplemental external beam radiotherapy, the patients in our implant population received relatively high dose escalation. Using the AAPM radiobiological formalism [11], 86.4 Gy of prostate external beam radiation has a BED of $131 \mathrm{~Gy}$, while the mean total BED for our population ranged from $133 \mathrm{~Gy}$ for low risk men to $157 \mathrm{~Gy}$, and $164 \mathrm{~Gy}$ in intermediate and high risk men, respectively (Table 1).

In patients with positive biopsies at the prostate base treated with brachytherapy monotherapy at M.D. Anderson, the 10-year biochemical progression free survival as $93.5 \%$, and all failures occurred prior to 6 years [18]. A much larger population in a recent report by Morris et al. [19] on brachytherapy monotherapy in low and interme- diate risk patients with median and maximum follow up of 7.5 years, and 13 years had $16 \%$ of failures occurring at $<3$ years and $10 \%>8$ years. Using only ${ }^{125}$ I seeds, their mean $\mathrm{D}_{90}$ was $151 \mathrm{~Gy}$ which translates to an AAPM BED of 116 Gy. In our low to intermediate risk cohort, 58.6\% $(34 / 58)$ of failures were within 3 years, while only 2 patients failed after 8 years.

Our rate of early treatment failures is roughly similar to the rates in the more recent external beam dose escalation studies. However, the rate of late treatment failures is much lower in our series than in those studies. The recent dose escalated external beam series have a high proportion of treatment failures five or more years after treatment; whereas $91 \%(84 / 92)$ of treatment failures in our series occurred within the first 5 years. This supports the hypothesis that in modern cohorts, even among men with high risk disease, the number of men who experience early failures and are "incurable" due to presence of occult metastases prior to treatment is quite small. As well, it would appear that most late treatment failures in current dose escalated external beam series are not the result of untreated 
occult metastases; but more likely due to inadequate dose escalation. We view this optimistically, that with current combined modality dose escalation techniques, outcomes for high risk and intermediate risk patients can be significantly improved through a reduction of late failures. This builds on a line of reasoning dating back to Fuks et al. [20] in 1991, who found that even in men undergoing retropubic brachytherapy implants, durable local control led to a substantial reduction in development of metastases.

\section{Limitations}

The strengths of this work are that low, intermediate and high risk patients were treated with a consistent implant philosophy and pattern of dose escalation, that the dose escalation parameters were well documented, and that no patients were lost to follow up. In general, lower risk patients received high quality brachytherapy-alone with day $0 \mathrm{D}_{90}$ s of approximately $120 \%$. Higher risk patients received supplemental external beam radiotherapy, followed by equally high quality implants with day $0 D_{90} S$ of approximately $120 \%$. One limitation is that this study was not a randomized trial comparing TTF between dose escalated brachytherapy with and without external beam radiotherapy versus dose escalated external beam radiotherapy alone. In addition, although the premise that early biochemical failures are due to subclinical distant metastases at diagnosis, this remains unproven due to the inability of current radiographic technologies to identify such early metastatic disease. Nevertheless, based on the results above, we feel comfortable with the conclusion that there is a low burden of micro-metastatic disease at presentation in modern day patient cohorts similar to ours; and that effective dose escalation with brachytherapy can lead to very successful treatment outcomes.

\section{Conclusions}

Aggressive radiation dose escalation provided by brachytherapy for men with low, intermediate, and high risk disease leads to low levels of late treatment failures. This supports the hypothesis that the great majority of prostate cancer patients, even those with high risk disease are without micro-metastatic disease on presentation, and therefore are potentially curable with adequate dose escalation.

\section{Disclosure}

Authors report no conflict of interest.

\section{References}

1. Buyyounouski MK, Pickles T, Kestin LL et al. Validating the interval to biochemical failure for the identification of potentially lethal prostate cancer. J Clin Oncol 2012; 30: 1857-1863.

2. Kapadia NS, Olson K, Sandler HM et al. Interval to biochemical failure as a biomarker for cause-specific and overall survival after dose-escalated external beam radiation therapy for prostate cancer. Cancer 2012; 118: 2059-2068.

3. Shilkrut M, McLaughlin PW, Merrick GS et al. Interval to biochemical failure predicts clinical outcomes in patients with high-risk prostate cancer treated by combined-modality radiation therapy. Int J Radiat Oncol Biol Phys 2013; 86: 721-728.
4. Freedland SJ, Humphreys EB, Mangold LA et al. Risk of prostate cancer-specific mortality following biochemical recurrence after radical prostatectomy. JAMA 2005; 294: 433-439.

5. Kuban DA, Tucker SL, Dong L et al. Long-term results of the M. D. Anderson randomized dose-escalation trial for prostate cancer. Int J Radiat Oncol Biol Phys 2008; 70: 67-74.

6. Zelefsky MJ, Pei X, Chou JF et al. Dose escalation for prostate cancer radiotherapy: predictors of long-term biochemical tumor control and distant metastases-free survival outcomes. Eur Urol 2011; 60: 1133-1139.

7. Merrick GS, Butler WM. Modified uniform seed loading for prostate brachytherapy: rationale, design, and evaluation. Tech Urol 2000; 6: 78-84.

8. Merrick GS, Butler WM, Wallner KE et al. Extracapsular radiation dose distribution after permanent prostate brachytherapy. Am J Clin Oncol 2003; 26: e178-189.

9. Stock RG, Stone NN, Tabert A et al. A dose-response study for I-125 prostate implants. Int J Radiat Oncol Biol Phys 1998; 41: 101-108.

10. Wallner K, Merrick G, True L et al. 125I versus 103Pd for lowrisk prostate cancer: preliminary PSA outcomes from a prospective randomized multicenter trial. Int J Radiat Oncol Biol Phys 2003; 57: 1297-1303.

11. Nath R, Bice WS, Butler WM et al. AAPM recommendations on dose prescription and reporting methods for permanent interstitial brachytherapy for prostate cancer: report of Task Group 137. Med Phys 2009; 36: 5310-5322.

12. Kuban DA, Levy LB, Potters L et al. Comparison of biochemical failure definitions for permanent prostate brachytherapy. Int J Radiat Oncol Biol Phys 2006; 65: 1487-1493.

13. D'Amico AV, Whittington R, Malkowicz SB et al. Biochemical outcome after radical prostatectomy, external beam radiation therapy, or interstitial radiation therapy for clinically localized prostate cancer. JAMA 1998; 280: 969-974.

14. Kestin LL, Vicini FA, Ziaja EL et al. Defining biochemical cure for prostate carcinoma patients treated with external beam radiation therapy. Cancer 1999; 86: 1557-1566.

15. Bolla M, Collette L, Blank L et al. Long-term results with immediate androgen suppression and external irradiation in patients with locally advanced prostate cancer (an EORTC study): a phase III randomised trial. Lancet 2002; 360: 103-106.

16. Zietman AL, Bae K, Slater JD et al. Randomized trial comparing conventional-dose with high-dose conformal radiation therapy in early-stage adenocarcinoma of the prostate: long-term results from proton radiation oncology group/ american college of radiology 95-09. J Clin Oncol 2010; 28: 1106-1111.

17. Shilkrut M, Merrick GS, McLaughlin PW et al. The addition of low-dose-rate brachytherapy and androgen-deprivation therapy decreases biochemical failure and prostate cancer death compared with dose-escalated external-beam radiation therapy for high-risk prostate cancer. Cancer 2013; 119: 681-690.

18. Samuelian JM, Swanson DA, Kudchadker RJ et al. Long-term tumor control after brachytherapy for base-of-prostate cancer. J Contemp Brachytherapy 2011; 3: 183-187.

19. Morris WJ, Keyes M, Spadinger I et al. Population-based 10-year oncologic outcomes after low-dose-rate brachytherapy for low-risk and intermediate-risk prostate cancer. Cancer 2013; 119: 1537-1546.

20. Fuks Z, Leibel SA, Wallner KE et al. The effect of local control on metastatic dissemination in carcinoma of the prostate: long-term results in patients treated with $125 \mathrm{I}$ implantation. Int J Radiat Oncol Biol Phys 1991; 21: 537-547. 